\title{
METAIS PESADOS: FONTE E AÇÃO TOXICOLÓGICA
}

\author{
Flávio Fernando Manzini ${ }^{1}$
}

Kaoara Batista de Sá2

\section{Lídia Maria de Almeida Plicas ${ }^{3}$}

Resumo: A contaminação do solo pelo descarte de substâncias tóxicas adquiriu, nos últimos anos, maior atenção da comunidade científica a qual tem alertado a população dos países, em geral, para as conseqüências, em especial, as patologias que podem ocorrer quando estas substâncias adentram nossa cadeia alimentar. Neste trabalho procurou-se apresentar as fontes de contaminação e a toxicidade do cádmio, do chumbo, do mercúrio e do manganês, quando estes se encontram em níveis elevados no solo e nos mananciais superficiais e subterrâneos. Com relação aos três primeiros metais, sua alta dosagem pode provocar, no ser humano, diversos tipos de câncer, lesões no estômago e pulmões, além de alterações importantes nos sistemas imunológico e nervoso central. O manganês, um dos metais mais comuns da crosta terrestre, largamente utilizado pela indústria e disponibilizado, em grandes quantidades no meio ambiente, em doses elevadas pode causar doenças pulmonares e neurológicas.

Palavras-chave: Metais pesados. Fonte. Toxicidade.

\section{INTRODUÇÃO}

\footnotetext{
${ }^{1}$ Doutor em Geologia Regional, Instituto de Biociências, Letras e Ciências Exatas, UNESP-SP fmanzini@ibilce.unesp.br

${ }^{2}$ Bacharel em Química Ambiental, Instituto de Biociências, Letras e Ciências Exatas, UNESP-SP kaoara@hotmail.com

${ }^{3}$ Doutora em Química, Instituto de Biociências, Letras e Ciências Exatas, UNESP-SP

plicas@ibilce.unesp.br
} 
O solo é formado por uma camada superficial de alguns centímetros e por outras, sucessivamente, mais profundas. Em geral, as características do solo variam com a profundidade, em razão das diferenças de temperaturas, teor de água, concentração de gases (particularmente oxigênio e gás carbônico) e movimento descendente de solutos e de partículas, ou seja, por fluxos de material formando diferentes camadas (denominadas horizontes). A camada superior do solo, conhecida como horizonte $\mathbf{A}$, em geral com espessuras entre 1 e 2 metros, é, comumente, a mais escura, contendo a maior concentração de matéria orgânica. Num solo espesso os componentes inorgânicos dessa camada de topo são a argila e os minerais insolúveis como o quartzo. Sotoposta a esta se encontra o horizonte $\mathbf{B}$, onde a matéria orgânica é esparsa. Os minerais solúveis e os óxidos de ferro podem se acumular sob a forma de finas lentes. A camada inferior, o horizonte C, é o substrato rochoso, fragmentado e em diversos graus de decomposição, misturado com a argila do intemperismo químico (PRESS et. al., 2006). A utilização, de maneira não apropriada, de defensivos agrícolas, de águas de irrigação de baixa qualidade e a disposição indiscriminada de resíduos industriais ou domésticos pode provocar, por exemplo, o acúmulo no solo de substâncias impróprias, em especial, metais pesados, que podem ser tóxicas para plantas podendo entrar na cadeia alimentar, afetando o ser humano (GUARACHO et. al., 2004). (Figura 1).

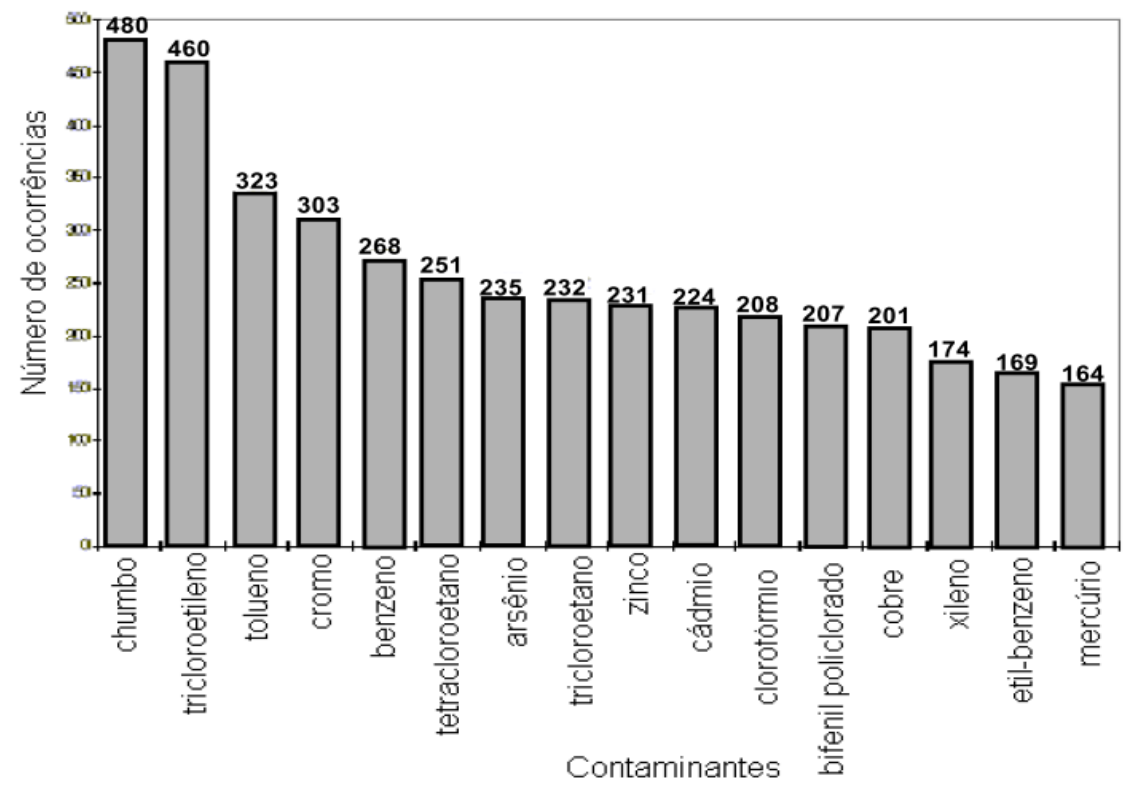


Figura 1. Contaminantes mais comuns nos solos (EPA, 1997 apud PEDRAZZOLI, 2004).

Metais pesados são elementos de alta densidade, em comparação a outros elementos comuns, apresentam densidade igual ou superior a $5 \mathrm{~g} / \mathrm{cm}^{3}$, e número atômico maior que 20 (MARQUES et al., 2002 apud SOARES, 2004). Essa expressão "metais pesados", de definição muito criticada e controvertida, é utilizada na literatura relacionada a metais, semi-metais e não-metais. São utilizados como sinônimos, "metais traço", "elementos traço", "micronutrientes", "microelementos", entre outros (ADRIANO, 1986; POVINELLI, 1987; EGREJA FILHO, 1993 apud DUARTE \& PASQUAL, 2000). Dentre eles, o mercúrio, o chumbo, o cádmio e o arsênio, em suas formas iônicas ou orgânicas, são altamente tóxicos ao ser humano, mesmo em baixas concentrações (WHO, 1996 apud SOARES, 2004). A toxicidade desses metais depende muito de sua especiação. $O$ manganês é um dos metais pesados mais comuns nos solos (MELFI et al. 1979 apud FADIGAS et. al., 2002).

A Tabela 1 apresenta os valores orientadores para cádmio, chumbo e mercúrio, em solos no Estado de São Paulo. A CETESB não apresenta valores orientadores para o manganês.

Tabela 1: Valores orientadores para solo no Estado de São Paulo.

\begin{tabular}{|c|c|c|c|c|c|c|}
\cline { 2 - 7 } \multicolumn{2}{c|}{} & \multicolumn{5}{c|}{ Solo (mg/kg de peso seco) } \\
\hline Substância & CAS № & $\begin{array}{c}\text { Referência } \\
\text { de } \\
\text { qualidade }\end{array}$ & Prevenção & $\begin{array}{c}\text { Agrícola } \\
\text { APMax }\end{array}$ & Residencial & Industrial \\
\hline Cádmio & $7440-48-$ & $<0,5$ & 1,3 & 3 & 8 & 20 \\
\hline Chumbo & $\begin{array}{c}7440-43- \\
9\end{array}$ & 17 & 72 & 180 & 300 & 900 \\
\hline Manganês & $7439-96-$ & - & - & - & - & - \\
\hline Mercúrio & $5439-97-$ & 0,05 & 0,5 & 12 & 36 & 70 \\
& 6 & & & & & \\
\hline
\end{tabular}


Fonte: CETESB, 2005 (modificada).

Atualmente, tem-se dado cada vez mais importância à preservação ambiental, de modo geral. Dentro deste contexto, o solo, um microuniverso estruturado no qual convivem a fração mineral, a água e o ar e, portanto, imprescindível à vida, tem merecido destaque, uma vez que, nem sempre seu manejo é realizado de forma correta. $O$ constante descarte de materiais nocivos tem resultado na sua contaminação e, consequentemente, na contaminação de populações.

Com base nesta prerrogativa, procurou-se, neste trabalho apresentar as conseqüências da contaminação de solos por quatro metais importantes e comuns no uso diário, na indústria e na agricultura, entre outros.

\section{DESENVOLVIMENTO}

Esta pesquisa foi realizada através de consultas à bibliografia pertinente, na forma de livros e periódicos específicos. O meio eletrônico também foi utilizado como suporte, nesta compilação. Dessa forma, são apresentados, a seguir, os resultados encontrados para os metais cádmio, chumbo, manganês e mercúrio.

\subsection{Cádmio}

O Cádmio é um metal de número atômico 48 e símbolo Cd que pode apresentar-se na cor prata-esbranquiçado ou azulado e pertence, juntamente com o mercúrio e o zinco, ao grupo 13 da Tabela Periódica (WIKIPÉDIA).

\subsubsection{Fontes de cádmio}

Pequenas quantidades de cádmio são encontradas naturalmente no ar, na água, no solo e nos alimentos (WIKIPÉDIA). Calcula-se que a cada ano sejam liberados no meio ambiente entre 25.000 e 30.000 toneladas de cádmio, sendo que cerca da metade é proveniente da erosão das rochas que chegam aos rios, e posteriormente aos oceanos (ATSDR). As rochas sedimentares e rochas fosfáticas de origem marinha são as principais fontes naturais do metal. A atividade vulcânica, tanto em superfície, quanto em mar profundo, é o principal mecanismo de lançamento de cádmio na atmosfera. Outra 
fonte natural de emissão do metal ao ar são os incêndios florestais (CADMIUM ASSOCIATION, 2000 apud CARDOSO \& CHASIN, 2001). As emissões ocorrem para o ar, água e solo, e o intercâmbio entre os três meios é considerado importante. O montante emitido no ar tem maior mobilidade do que na água, que por sua vez é maior que no solo (WHO, 1992 apud CARDOSO \& CHASIN, 2001). Outras importantes fontes de liberação são a queima de combustíveis fósseis, no lixo urbano e industrial uma vez que está presente, por exemplo, em pilhas elétricas e nos plásticos e em fertilizantes que o contem (ATSDR).

\subsubsection{Ação toxicológica do cádmio}

A toxicidade do cádmio, por ser similar em humanos e animais, pode ser avaliada por estudos de investigação experimental em ratos, camundongos, coelhos e macacos. Ela também é similar para os diferentes sais e óxidos de cádmio e, embora diferentes em termos da absorção e distribuição, levam aos mesmos efeitos, porém de intensidade diferente devido à cinética (CARDOSO \& CHASIN, 2001).

O cádmio pode entrar no corpo humano através dos alimentos, da água ou das partículas suspensas no ar que respiramos, assim como pela inalação da fumaça do cigarro. É pouco provável que o cádmio entre no corpo através da absorção cutânea (ATSDR). Esse metal é considerado um poluente persistente e acumula-se principalmente nos rins e no fígado de mamíferos provocando irritações graves no estômago, vômitos e diarréias, enfraquecimento dos ossos, tornando-os mais vulneráveis às fraturas e até a morte. Não foram realizados estudos sobre o efeito teratogênico desse metal em humanos. Porém, em animais que 0 ingeriram por via oral, pesquisas observaram o aumento da pressão arterial, a diminuição dos níveis de ferro no sangue, enfermidades hepáticas e danos cerebrais ou ao sistema nervoso central. Não há estudos conclusivos sobre os níveis mínimos de cádmio na comida e na bebida que causariam, ou não, estas enfermidades nas pessoas. De qualquer forma, a Agência Internacional para a Pesquisa do Câncer (IARC) determinou que o cádmio é carcinogênico para os seres humanos (ATSRD).

\subsection{Chumbo}


O Chumbo é um metal de número atômico 82, símbolo $\mathrm{Pb}$ e se apresenta cinzaazulado, inodoro, maleável, sensível ao ar. Pertence ao grupo 14 da Tabela Periódica. Está, geralmente, associado a outros minérios, principalmente, aos que contêm zinco, cobre e prata (WHO, 1989 apud NASCIMENTO \& CHASIN, 2001).

Devido a problemas de contaminação ambiental e por sua toxidez ao ser humano, o consumo do chumbo vem diminuindo de forma acentuada nos países industrializados, e ao mesmo tempo, vêm se desenvolvendo substitutos desse metal por outros produtos com menor toxicidade (OLIVEIRA, 2003). A contaminação por chumbo ocorre, especialmente, por emissões atmosféricas, e nesse caso, a contaminação antropogênica é predominante (ATSDR, 1993 apud NASCIMENTO \& CHASIN, 2001).

\subsubsection{Fontes de chumbo}

As maiores fontes naturais de chumbo são emissões vulcânicas e névoas aquáticas. É encontrado, também, em rochas ígneas e metamórficas sendo liberado destas após intemperismo geoquímico, na forma de sulfeto de chumbo (galena) que é a mais importante fonte primária do metal e a principal fonte comercial. Está, geralmente, associado a outros minérios, principalmente, aos que contêm zinco, cobre e prata (WHO, 1989 apud NASCIMENTO \& CHASIN, 2001).

O chumbo é um dos contaminantes mais comuns do ambiente, devido às inúmeras atividades industriais que favorecem a sua grande distribuição. As fontes mais significativas de emissão deste metal são as fundições primárias e secundárias, as fábricas e reformadoras de baterias (WHO, 1992 apud QUITERIO et. al., 2006), também as indústrias extrativa, petrolífera, de acumuladores, de tintas e corantes, de cerâmica e bélica, além da constante emissão por veículos automotores pela combustão da gasolina, que contém o metal. Todos estes processos provocam o aumento das concentrações no solo e na poeira em áreas vizinhas. (LARINI, 1987; NRIAGU, 1988 apud DUARTE \& PASQUAL, 2000). O chumbo, assim liberado pode, também, estar presente no lodo de esgoto que poderá ser utilizado como adubo ou fonte de nutrientes na agricultura, tornando-se, assim, mais um agente contaminante do solo (OLIVEIRA \& MATTIAZZO, 2001). A Tabela 2 apresenta dados da emissão mundial de chumbo, proveniente de variadas fontes, para o solo. 
Tabela 2. Emissão mundial de chumbo para o solo, proveniente de variadas fontes, em 1983.

\begin{tabular}{|c|c|}
\hline Categoria da fonte & Taxa de emissão (ton $/ \mathrm{m}^{3}$ ) \\
\hline Resíduos da agricultura e alimentos & 26 \\
\hline Resíduos de madeira & 7,4 \\
\hline Dejetos urbanos & 40 \\
\hline Esgoto & 7,1 \\
\hline Resíduos do solo da fabricação de metais & 7,6 \\
\hline Cinzas de carvão & 144 \\
\hline Produtos descartados & 292 \\
\hline Fertilizantes e turfas & 2,9 \\
\hline Sedimentação da atmosfera & 232 \\
\hline Total de contribuição para o solo & 759 \\
\hline
\end{tabular}

Fonte: DUDKA; MILLER, 1999 apud PAOLIELLO, 2001.

\subsubsection{Ação toxicológica do chumbo}

As vias respiratórias e gastrintestinais são as principais portas de entrada do chumbo no organismo humano sendo que, a poeira, o solo, os alimentos e a água são as formas mais significativas de ingestão (ATSDR, 1999 apud MOREIRA \& MOREIRA, 2004; WHO, 1989 apud NASCIMENTO \& CHASIN, 2001). Após absorvido, o chumbo pode ser encontrado no sangue, nos tecidos moles (fígado, rins, pulmões, cérebro, baço, músculos e coração) e nos tecidos mineralizados (ossos e dentes) (ATSDR, 1999 apud MOREIRA \& MOREIRA, 2004).

O chumbo não possui nenhuma função fisiológica conhecida no organismo, e seus feitos tóxicos sobre os homens e animais já são conhecidos há muito tempo (XIE et. al., 1998 apud MOREIRA \& MOREIRA, 2004). O metal pode afetar, praticamente, todos os órgãos e sistemas do organismo humano, incluindo alterações nos sistemas neurológico, hematológico, metabólico e cardiovascular. A redução do QI (quociente de inteligência), dificuldades de aprendizagem ou problemas de comportamento são conseqüências da exposição ao chumbo por longos períodos de tempo, mesmo a níveis baixos. O feto é 
muito sensível aos efeitos da exposição, portanto, as mulheres grávidas devem ter especial cuidado (ATSDR, 1992 apud MOREIRA \& MOREIRA, 2004; WIKIPÉDIA).

O sistema nervoso central (SNC) é o conjunto mais afetado pelo metal. Esse fato é atribuído à alteração de enzimas e proteínas estruturais, entre outros. Além do SNC, a medula óssea e os rins também são muito afetados pelo chumbo (SILVA; MORAES, 1987 apud DUARTE \& PASQUAL, 2000). O cálcio é um componente crítico de numerosas funções bioquímicas e metabólicas e o chumbo, no cérebro, tem a capacidade de mimetizar e competir com o cálcio alterando essas funções (WIKIPÉDIA, 2008).

No Brasil, o controle das fontes de poluição de chumbo é quase inexistente devido à falta de dados sobre a real exposição da população ao metal (MOREIRA \& MOREIRA, 2004). KABATA-PENDIAS \& PENDIAS (1992) apud ABREU et. al. (1998), reportaram que, devido à entrada do chumbo na cadeia alimentar do homem, muito se tem investigado sobre o destino desse metal no solo. A contaminação de solos com chumbo é um processo cumulativo e, quase, irreversível por isso, os teores desse metal na superfície têm aumentado, indicando uma disponibilidade de absorção do mesmo pelas raízes das plantas. Os níveis naturais de chumbo em solos rurais apresentam-se, normalmente, em concentrações menores do que 30 ppm, entretanto, nos arredores das grandes cidades, em áreas próximas a fundições ou a rodovias com alto tráfego, estas concentrações podem exceder a 10.000 ppm (BELLINGER; SAVITZ, 1997 apud NASCIMENTO \& CHASIN, 2001).

\subsection{Manganês}

O manganês é um elemento químico, de símbolo Mn, com número atômico 25 e sólido em temperatura ambiente. É um metal de transição do grupo 7 da tabela periódica (WIKIPÉDIA). Como os demais elementos de transição, possui algumas propriedades características: apresenta várias formas e estados de oxidação $(0 \mathrm{a}+7)$ e pode formar vários compostos coloridos e paramagnéticos (WHO, 1981 apud MARTINS \& LIMA, 2001). É um metal que se apresenta sólido, frágil e quebradiço sendo, facilmente, oxidável É o terceiro metal mais abundante na crosta terrestre, depois do alumínio e do ferro estando amplamente distribuído (WIKIPÉDIA). 
Sua ocorrência nos solos brasileiros é predominantemente pedogênica (BORKERT et. al., 2001 apud CARDOSO et. al., 2003), com teores disponíveis que variam de 3 a 190 $\mathrm{mg} / \mathrm{dm}^{3}$. Esta concentração ocorre nos horizontes superficiais de solos do Estado de São Paulo (VALADARES; CAMARGO, 1981 apud CARDOSO et. al., 2003). Muito provavelmente, será maior nas camadas mais profundas.

\subsubsection{Fontes de manganês}

É um elemento natural que se encontra facilmente nas rochas. Apresenta-se em quatro formas alotrópicas: alfa, beta, gama e delta (WHO, 1981; BARCELOUX, 1999 apud MARTINS \& LIMA, 2001). Não ocorre em sua forma pura. Ocorre combinado com outros elementos como o oxigênio, enxofre e cloro. Estes compostos são sólidos que não se evaporam. Pequenas partículas de pó desse material sólido podem existir suspensas no ar e, além disso, alguns compostos podem dissolver-se na água sendo detectados, por vezes, baixos teores dos mesmos em lagos, riachos e oceanos. O manganês pode transformar-se de um composto a outro, mas não se degrada e nem desaparece do ambiente (ATSDR). É encontrado em centenas de minerais, embora apenas uma dezena apresente interesse comercial. Destacam-se a: pirolusita $\left(\mathrm{MnO}_{2}\right)$, psilomelano $\left(\mathrm{MnO}_{2} \cdot \mathrm{H}_{2} \mathrm{O}\right)$, manganita $(\mathrm{MnO}(\mathrm{OH}))$, braunita $\left(3 \mathrm{Mn}_{2} \mathrm{O}_{3} \cdot \mathrm{MnSiO}_{3}\right)$, rodonita $\left(\mathrm{MnSiO}_{3}\right)$, rodocrosita $\left(\mathrm{MnCO}_{3}\right)$, hübnerita $\left(\mathrm{MnWO}_{4}\right)$, e outros. Também ocorre no leito marinho, na forma de nódulos, onde o conteúdo de manganês oscila entre 15 e 30\%. Há possibilidade de aproveitamento econômico dessa forma de ocorrência (WIKIPÉDIA).

Os compostos de manganês podem ser classificados em: orgânicos e inorgânicos. Entre as formas inorgânicas incluem-se as que se encontram nos produtos de combustão no escapamento de automóveis ou caminhões e nos pós que estão presentes na produção de aço ou baterias. As formas orgânicas de manganês são, principalmente, os aditivos para a gasolina, para os praguicidas, e um composto usado em hospitais para se diagnosticar alguns tipos de câncer (ATSDR).

\subsubsection{Ação toxicológica do manganês}


O manganês é um elemento essencial para a saúde. O corpo humano contém pequenas quantidades do mesmo e, em condições normais, as mantém em níveis adequados (ATSDR).

Os seres humanos estão expostos ao manganês nos alimentos e na água que ingerem e no ar que respiram. As crianças amamentadas ingerem manganês presente no leite materno, em fórmulas infantis a base de soja ou em leite de vaca. A quantidade de manganês nestas fontes geralmente não apresenta problema, e fornecem a quantidade de manganês necessária para o funcionamento normal do organismo. Porém, nas proximidades de locais de descarte de agentes contaminantes, há a possibilidade de exposição a níveis mais altos de manganês uma vez que estes resíduos ficam disponibilizados no solo, na água ou em material particulado. A contribuição destas rotas de exposição aos efeitos tóxicos do manganês é incerta, porém, efeitos adversos foram observados em pessoas expostas a níveis ambientais muito altos de manganês, através das mesmas. Entre 3 e 5\% do metal ingerido permanece no corpo (ATSDR).

Em humanos, o manganês é absorvido no intestino delgado, acabando a maior parte no fígado, de onde se dirige para as diferentes partes do organismo. Sua carência nos humanos pode causar: perda de peso, fragilidade óssea, dermatite, degeneração do ovário ou testículos e náuseas. Seu excesso (em nível de nutriente) nos humanos pode causar: anorexia, alucinações, dificuldade de memorização, insônia e dores musculares (WIKIPÉDIA). Destaca-se que, de acordo com BARCELOUX (1999) apud MARTINS \& LIMA (2001), o manganês, em doses elevadas, absorvido tanto oralmente, quanto pela epiderme, pode provocar doenças pulmonares e neurológicas.

Reportando-se à Tabela 1, se verifica que não há parâmetros orientadores para o teor de manganês, nos solos, do Estado de São Paulo, definidos pela CETESB.

\subsection{Mercúrio}

O mercúrio $(\mathrm{Hg})$ é um metal líquido e algo volátil a temperatura ambiente, apresenta número atômico 80. Raramente ocorre livre na natureza, e sua forma mais freqüente de ocorrência é no cinábrio, um mineral constituído por sulfeto de mercúrio (HgS). Na sua forma elementar, nas condições normais de temperatura e pressão, é um líquido denso, prateado e inodoro. É um metal de transição e pertence ao grupo 12, da 
Tabela Periódica, juntamente com o cádmio e o zinco. É encontrado, normalmente, em dois estados de oxidação. Está amplamente distribuído na crosta terrestre, porém em concentrações baixas, sendo que, suas reservas são estimadas em 30 bilhões de toneladas. Pode ser encontrado em três formas primárias: mercúrio elementar ou metálico em estado de oxidação zero $\left(\mathrm{Hg}^{0}\right)$, inorgânico de oxidação $1+\left(\mathrm{Hg}_{2}{ }^{2+}\right)$ e de oxidação 2+ $\left(\mathrm{Hg}^{2+}\right)$, que formam compostos químicos orgânicos (com ligações a átomos de carbono) e inorgânicos (WHO, 1976; YIP et. al., 2001 apud FERRER, 2003; ALMEIDA, 2005).

O mercúrio é calcófilo (interage bem com o enxofre), e é ativo biologicamente (ALMEIDA, 2005). Com o aumento da temperatura transforma-se em vapores tóxicos e corrosivos que são mais densos que o ar. Se inalado, ingerido ou em contato com a pele é tóxico, causando irritação nos olhos, na pele e nas vias respiratórias (WIKIPÉDIA).

Os compostos orgânicos de mercúrio são importantes e perigosos, sendo o metilmercúrio a forma mais contaminante deste metal no meio ambiente (ALMEIDA, 2005).

O mercúrio elementar está presente em numerosos instrumentos de medida (termômetros, barômetros e outros), interruptores e tubos cirúrgicos especiais, bem como nas amálgamas dentarias (WHO, 1976; YIP et. al., 2001 apud FERRER, 2003). Também é muito usado como catalisador de reações químicas e na mineração de ouro e prata (WIKIPÉDIA).

\subsubsection{Fontes de mercúrio}

As fontes naturais mais significativas de mercúrio são: a gaseificação da crosta terrestre, as emissões de vulcões e a evaporação de corpos aquáticos. Admite-se que as emissões naturais sejam da ordem de 25.000 a 125.000 toneladas por ano. As fontes do minério cinábrio (HgS), são as rochas próximas a zonas vulcânicas mais recentes, em fraturas minerais e próximas a fontes de águas termais (CARDOSO \& CHASIN, 2001; WIKIPÉDIA).

O mercúrio pode estar associado a hidrocarbonetos gasosos e líquidos (petróleo, betumes) e também a jazidas de carvão mineral. Origina-se nas profundezas do manto terrestre e, possivelmente, ascende à superfície nas suas formas orgânicas: metil ou dimetil mercúrio (WIKIPÉDIA). 
Calcula-se que a liberação antropogênica ambiental do mercúrio, seja em torno de 2.000 toneladas ao ano (ATSDR, 1992 apud FERRER, 2003) como resultado de atividade mineradora, de resíduos industriais da produção de cloro-álcali ou da fabricação de vinil e fungicidas, das pinturas antifúngicas, da fotografia, da pirotecnia, das baterias secas e das pilhas, das indústrias de papel e dos laboratórios médico-veterinários e dentais (como anti-séptico e na obturação de dentes) além das refinarias, das fábricas de adubos, do contido em lâmpadas de vapor de mercúrio e, principalmente, dos incineradores de resíduos hospitalares e urbanos (WHO, 1989; LAUWERYS, 1990 apud FERRER, 2003; WIKIPÉDIA).

A presença de mercúrio em fungicidas, inseticidas e herbicidas é relativamente baixa, porém, essa fonte emite o metal diretamente ao solo, que pode ir para as plantas, para mananciais ou para a atmosfera (CARDOSO \& CHASIN, 2001). A poluição da Amazônia por esse metal representa um enorme problema ambiental, pois são lançadas ao ambiente, devido à mineração do ouro e aos incêndios florestais, até 170 toneladas de mercúrio por ano (PFEIFER et. al., 1990 apud CARDOSO \& CHASIN, 2001).

Outra fonte de mercúrio para o ambiente é o lixo urbano, que contém esse metal proveniente de variadas fontes e que contamina o composto orgânico (produto da reciclagem da parte orgânica do lixo) e o chorume, que pode infiltrar-se no solo alcançando as águas subterrâneas ou ser lançado diretamente em mananciais (CARDOSO \& CHASIN, 2001). Da mesma forma, os esgotos e lodos de estações de tratamento, podem conter mercúrio e contaminar estes mananciais (PAGANINI et. al., 2004).

\subsubsection{Ação toxicológica do mercúrio}

O mercúrio que vai para os mananciais pode se acumular em plantas aquáticas, invertebrados, peixes e mamíferos, fazendo parte, então, da cadeia alimentar. Devido ao processo de oxidação que sofre, ele fica em solução e muito estável em ambientes aquáticos. A formação de complexos organomercuriais, na presença de óxidos orgânicos, contribui para aumentar a disponibilidade desse metal (CARDOSO \& CHASIN, 2001).

Níveis normais de mercúrio no sangue são inferiores a $10 \mu \mathrm{g} / \mathrm{L}$ e na urina são inferiores a $20 \mu \mathrm{g} / \mathrm{L}$ (SUE, 1998 apud FERRER, 2003). A concentração de até $1 \mu \mathrm{g} / \mathrm{L}$, na 
água, é considerada aceitável pela OMS, e a ingestão semanal tolerável desse metal total é de $5 \mu \mathrm{g} / \mathrm{kg}$ e de 3,3 $\mu \mathrm{g} / \mathrm{kg}$, da sua forma orgânica (metil-mercúrio) (WHO, 1976 apud FERRER, 2003).

As intoxicações por mercúrio apresentam uma graduação de efeitos proporcionais a sua ingestão e/ou acumulação (WIKIPÉDIA).

A principal via de absorção do mercúrio elementar é a inalação do seu vapor. Nesse caso, são absorvidos até $75 \%$ da dose inalada. A sua absorção pelo tubo digestivo é muito baixa, menos que $0,01 \%$ do ingerido e sua penetração pela pele é insignificante (HURSH et. al., 1976 apud FERRER, 2003).

Depois de absorvido, o mercúrio elementar é difundido pelo sangue e oxidado a íon mercúrico, essa oxidação é um processo reversível catalisado por enzimas (no caso, catalases peroxisomais). O metal que não foi oxidado é capaz de penetrar na placenta e na barreira hematoencefálica. A vida média dessa forma de mercúrio, no organismo, é de 60 dias, podendo ser eliminado pela via urinária ou digestiva, na forma de íon mercúrico, ou pela via pulmonar na forma de $\mathrm{Hg}^{0}$ vapor (MAGOS, 1988 apud FERRER, 2003).

O mercúrio inorgânico tem absorção importante pela via digestiva, cerca de 2 a 10\% do total de $\mathrm{ClHg}_{2}$ ingerido (LAUWERYS, 1900 apud FERRER, 2003), sendo esta via, a principal responsável por intoxicações agudas. Essa forma do metal é distribuída no sangue entre as hemácias e o plasma, e não consegue atravessar a barreia hematoencefálica. Tem uma vida média entre 30 e 60 dias e é eliminada pela via renal (MAGOS, 1988 apud FERRER, 2003).

As formas orgânicas de mercúrio podem ser absorvidas por todas as vias. O metilmercúrio é amplamente distribuído nos diferentes tecidos, preferencialmente onde há mais lipídios (cérebro e tecido adiposo). Essa forma do metal adentra o ciclo enterohepático, tendo prolongada sua vida média no organismo para até 70 dias, e é eliminada, sobretudo, pelas fezes (WINSHIP, 1986 apud FERRER, 2003).

Mesmo intoxicações mais leves por mercúrio são caracterizadas pelo aparecimento de sintomas, como anemia, anorexia, depressão, dermatite, fadiga, dores de cabeça, hipertensão, insônia, irritabilidade, tremores, fraquezas e problemas de audição e visão. Problemas neurológicos graves, inclusive paralisias cerebrais ocorrem devido a intoxicações mais severas e que, nesse caso, podem conduzir a óbito. O sistema nervoso 
central é o órgão mais vulnerável à contaminação por mercúrio, seguido pelo sistema renal e o pulmonar (SUE et. al., 1998 apud FERRER, 2003; WIKIPÉDIA).

\section{CONCLUSÃO}

Todos os metais pesquisados neste trabalho são, amplamente, utilizados no dia-adia, seja pela indústria, pela agricultura ou em medicamentos e alimentos. O problema reside no descarte dos resíduos destes materiais que, em grande parte, é realizado sem qualquer critério, desde há muito tempo. Estes metais têm-se acumulado nos solos, neste tempo todo. Tem sido escoados pelas enxurradas e carreados a maiores profundidades, pelas águas de percolação.

No solo podem adentrar nossa cadeia alimentar pela agricultura. Pela ação de transporte da água podem ser levados a mananciais superficiais e, em profundidade, podem contaminar os lençóis subterrâneos sendo que, nos dois casos comprometem a qualidade da água de consumo.

Destaca-se que, nem sempre, são efetuadas análises em solos e nas águas de superfície e subterrâneas para se detectar quantidades anormais destes contaminantes. Dessa forma, muitos núcleos populacionais, ainda consomem produtos agrícolas e água sem a menor noção do efeito prejudicial que os mesmos podem proporcionar. Cádmio, chumbo e mercúrio, são cancerígenos. Mesmo o manganês, em doses elevadas, é tóxico e poucos são os estudos já realizados sobre este fato.

Não foi objetivo deste estudo apresentar casos notificados de contaminação e os efeitos provocados, porém, no desenvolvimento do mesmo, nos deparamos com relatos de situações muito graves envolvendo óbitos. Portanto, a se continuar este descaso, é de se esperar um gradual aumento no número de pessoas atingidas por patologias severas. É muito provável, também, que muitas destas doenças, nesse futuro, ainda não tenham sido registradas.

\section{REFERÊNCIAS}

ABREU, C.A.; ABREU, M.F. \& ANDRADE, J.C. Distribuição de Chumbo no Perfil de Solo Avaliada Pelas Soluções de DTPA e MEHLICH-3. Bragantia, Campinas, v. 57 n. 1, 1998. 
(ATSDR) Agency for Toxic Substances and Disease Registry. Division of Toxicology and Environmental Medicine. Disponível em: <http://www.atsdr.cdc.gov/es/phs/es_ phs5.html>. Acesso em 13 de maio de 2008.

ALMEIDA, M.D. Biogeoquímica do Mercúrio na Interface Solo - Atmosfera na Amazônia. NITERÓI, 2005.

CARDOSO, E.J.B.N.; NAVARRO, R.B. \& NOGUEIRA, M.A. Seção III - Biologia do Solo Absorção e Translocação de Manganês por Plantas de Soja Micorrizadas, sob Doses Crescentes Deste Nutriente. Revista Brasileira de Ciência do Solo, v.27, p. 415-423, 2003.

CARDOSO, L.M.N. \& CHASIN, A.A.M. Ecotoxicologia do Cádmio e Seus Compostos. Cadernos de Referência Ambiental, Salvador, v. 6, p. 122, 2001.

CETESB - COMPANHIA DE TECNOLOGIA DE SANEAMENTO AMBIENTAL DECISÃO DE DIRETORIA. № 195-2005- E, de 23 de novembro de 2005. Dispõe sobre a aprovação dos Valores Orientadores para Solos e Águas Subterrâneas no Estado de São Paulo 2005, em substituição aos Valores Orientadores de 2001, e dá outras providências.

DUARTE, R.P.S. \& PASQUAL, A. Avaliação do Cádmio (Cd), Chumbo (Pb), Níquel (Ni) e Zinco (Zn) em Solos, Plantas e Cabelos Humanos. Energia na Agricultura, Botucatu, vol. 15, n. $1,2000$.

FADIGAS, F.S.; SOBRINHO, N.M.B.A.; MAZUR, N; ANJOS, L.H.C. \& FREIXO, A. A. Concentrações Naturais de Metais Pesados em Algumas Classes de Solos Brasileiros. Bragantia, Campinas, v. 61, n.2, maio/agosto 2002.

FERRER, A. Intoxicación por Metales. Anales Sis. San. Navarra, Pamplona, vol. 26, supl.1, p.141-153, 2003.

GUARACHO, V.V.; PONTE, M.J.J.S.; ADAMOSKI, L.F. \& OLIVEIRA, M. Utilização da Técnica de Remediação Eletrocinética para Remoção de Chumbo e Níquel de Solos de Landfarming de Refinaria de Petróleo. Instituto Brasileiro de Petróleo e Gás, Curitiba, 2004.

MARTINS, I. \& LIMA, I.V. Ecotoxicologia do Manganês e Seus Compostos. Cadernos de referência Ambiental, Salvador, v. 7, p. 121, 2001.

MOREIRA, F.R. \& MOREIRA, J.C. A cinética do chumbo no organismo humano e sua importância para a saúde. Ciência \& Saúde Coletiva, Rio de Janeiro, vol.1, n. 9, pág. 167-181, 2004.

NASCIMENTO, E.S. \& CHASIN A. A. M. Ecotoxicologia do chumbo e seus compostos. Cadernos de referência ambiental, Salvador, 2001, v. 3. 
OLIVEIRA, F.C. \& MATTIAZZO, M.E. Mobilidade de Metais Pesados em um Latossolo Amarelo Distrófico Tratado com Lodo de Esgoto e Cultivado com Cana-de-Açúcar.

Scientia Agrícola, Piracicaba, v.58, n.4, p.807-812, out./dez. 2001.

OLIVEIRA, R.C. Avaliação do Movimento de Cádmio, Chumbo e Zinco em Solo Tratado com Resíduo-Calcário. Lavras, 2003

PAGANINI, W.S.; SOUZA, A. \& BOCCHIGLIERI, M.M. Avaliação do Comportamento de Metais Pesados no Tratamento de Esgotos por Disposição no Solo. São Paulo, v. 9, n. 3, p. 225-239, jul/set 2004.

\section{PEDRAZOLLI, C.D. Remediação Eletrocinética de Chumbo em Resíduos Industriais.} Curitiba, 2004.

PRESS, F; SIEVER, R.; GROTZINGER, J. \& THOMAS, J.H. Para entender a Terra. Ed. Bookman, 4ed., 2006. 656p.

QUITERIO, S.L.; MOREIRA, F.R.; SILVA, C.R.S.; ARBILLA, G.; ARAÚJO, U.C. \& MATTOS, R.C.O.C. Avaliação da poluição ambiental causada por particulado de chumbo emitido por uma reformadora de baterias na cidade do Rio de Janeiro, Brasil. Cad. Saúde Pública, Rio de Janeiro, set, 2006.

SOARES M. R. Coeficiente de Distribuição (Kd) de Metais Pesados em Solos do Estado de São Paulo. (Tese de Doutorado. Escola Superior de Agricultura Luiz de Queiroz. Universidade de São Paulo). Piracicaba, 2004.

WIKIPÉDIA <http://pt.wipedia.org/wiki/C\%C3\%A1dmio> <http://pt.wipedia.org/wiki/chumbo > < http://pt.wipedia.org/wiki/Mangan\%C3\%AAs> < http://pt.wipedia.org/wiki/Merc\%C3\%BAro_\%28elemento_qu\%C3\%ADmico\%29>. Acesso: Fevereiro/Junho/2008. 